\title{
Regional Incentives to Increase the Competitiveness of a Renewable Energy Business Cluster in a Small Island Like Corsica (France)
}

\author{
Christophe STORAII, Christian CRISTOFARI \\ University of Corsica, Corte, France
}

\begin{abstract}
Renewable energy (RE) has grown to become part of mainstream economics, industry, and energy. The process started in the wake of oil shortages amid the 1970s energy crisis, when the major industrial countries of the world sought out an array of energy security strategies. Diversifying energy import-export trade, restructuring GDP, and increasing and backing home-sourced offers are all basic essential measures that different countries have adopted to different degrees in an effort to reduce dependency on imported oil. The last of these measures counts RE as a vector of local generation. The past decade has seen the RE sector really take off, driven by now well-structured industries starting to mobilize now-mature technologies. This developmental shift towards RE has been framed by different policy measures that nevertheless share the same core rationale climate change. Among the pro-renewables policies adopted by France, the deployment of competitive clusters has proved an effective tool for leveraging the growth of renewables. Business clusters are geographically-concentrated economic structures assuring the often tenuous link between efficient national industrial policy efforts and regional planning and branding issues. From this perspective, the logic of synergy by connecting global to local issues remains to be created around a new paradigm: regional attractiveness/place branding. In today's fast-globalizing world, the much-hyped concept of place branding has become critical for regions in fierce global competition to capture and secure geographically-mobile investment. In this context, promoting and attracting inward investment is a multidimensional challenge where business clusters have a pivotal role to play. Corsica, a small island economy, represents a case-in-point target of analysis through its long-standing plan for the regional and sustainable development of Corsica (French decentralization policy on Corsica under the law dated 22 January 2002) and the CAPENERGIES business cluster a key link in the technological research strand, entrusted with the overriding role of leading the island's transition toward decentralized energy independency. After having highlighted the specific characteristics of the Corsican island geographical area, this paper goes on to outline the joint-effect impacts of development of the CAPENERGIES competitive cluster in tandem with the process to find technology-centred solutions to drive development of the "renewable energy" industry in a small island economy like Corsica.
\end{abstract}

Keywords: energy, policy, regional branding, business cluster, local target of investments, territorial governance, technological research, globalization

Christophe STORAÏ, Senior Lecturer in Economics, UMR LISA 6234, University of Corsica.

Christian CRISTOFARI, Professor in Energy Physical, UMR LISA 6234, University of Corsica.

Correspondence concerning this article should be addressed to Christophe STORAÏ, CFA UNIV in Corsica area, Bât PPDB Campus Grimaldi 20250 Corte, France. E-mail: storai@univ-corse.fr. 


\section{Introduction}

The aim of this research is to bring further insights into potential synergies among knowledge management, innovation, technological research, applied vocational training and human capital development strategy and the barriers and constraints involved.

Based on its relevancy for energy and economic development policy, the business cluster case is presented as a model of this type of development in geographic island territory.

Chapter 17 of Agenda 21 (1992 Earth Summit in Rio de Janeiro) clearly states that islands are special configurations, both in terms of environment and development perspectives with specific issues, making them particularly fragile, vulnerable micro-economies. Within the framework of sustainable development policy, energy is the cornerstone of island-scale planning strategy. The traditional energy retail barriers, distance to grid networks, small-scale deployment, distribution challenges and the absence of traditional heavy-user markets, are more than comfortably offset by the extreme abundance of renewable energy (RE) sources and the outstanding ability of RE technologies to adapt and integrate. These factors are in stark contrast to the infrastructural inefficiency and high costs of conventional energy systems in island-based regions. Ultimately, islands need to develop into research platforms for test-trialling sustainable energy futures.

The authors of this review emphasize the importance of promoting effective coordination among research, training, and enterprise, well conscious of the potential global impact in areas as critical as RE development in island-territory planning.

Business clusters are geographically-concentrated economic structures assuring the often tenuous link between efficient national industrial policy efforts and regional planning and branding issues. In today's fast-globalizing world, business clusters also represent the French response to inherent constraints in order to increase competitiveness in the global marketplace, consistent with the desire of European authorities to construct a knowledge-based economy. ${ }^{1}$ Entry into the global economy does not preclude the issue of strictly-local development concerns. This apparent ambivalence, rooted in the concept of glocalization (Mair, 1994), is fully integrated into the progress of business clusters, whose ambition in a given geographic area is to interconnect businesses, research labs, training centres, government and local authorities, all of which synergistically partner up on innovative shared-focus projects (Jacquet \& Darmon, 2005).

Invariably, the very principle of a business cluster helps forge regional branding policy the new paradigm ushered in through globalization. Corsica, a small island economy, represents a case-in-point target of analysis through its long-standing Plan for the Regional and Sustainable Development of Corsica (PADDUC) project (French decentralization policy on Corsica under the law dated 22 January 2002) and the CAPENERGIES business cluster a key link in the technological research strand, entrusted with the overriding role of leading the island's transition toward decentralized energy independency. After first highlighting the characteristics of the Corsican island territory, this paper sets out to identify the specificities of a territorial governance policy built around the CAPENERGIES cluster from the perspective of the construction of a sustainable island branding plan, which is currently in search of foundations.

\footnotetext{
1 As Patrick DAMBRON states, "The birth of business clusters in France results from a joint effort by the European Union and the French State. Their definition is connected with the European framework. Their functional principles and their missions are, in fact, dictated by the objectives of the Lisbon strategy, even if they are adapted to national context, as with the DATAR-DIACT in France" (Dambron, 2009, p. 149).
} 


\section{Methodology and Literature Review}

The aim of this study is to compile arguments, experiences, and policies from countries around the world designed to promote RE. The literature review is important to gain a clear picture of existing tools to promote RE. Various authors have used a literature review approach to examine the impacts of the effectiveness of RE policy and development legislation, including Mitchell and Connor (2008) for the UK between 1990 and 2003, Cherni and Kentish (2007) for China, Lewis and Wier (2007) for the international development of wind turbines, Al-Amir and Abu-Hijleh (2013) for the United Arab Emirates, Hashim and Shin Ho (2011) for Malaysia (Tenth RE Plan 2011-2015), Mondola and Koumpetsosb (2013) for Greece and the Greek islands, Arnette and Zobel (2011) for RE development in the greater southern Appalachian mountains, Valle Costa, Rovere, and Assmann (2008) for Brazil through the Program to Encourage Alternative Energy Sources (PROINFA) based on EU experience in promoting RES-E and policy instruments adopted by the United Kingdom, the Netherlands, and Germany. Byrnes, Brown, Foster, and Wagner (2013) reported on Australian RE policy, presenting the key policy frameworks, incentives and regulatory landscape encompassing the RE sector and giving a critical analysis of the barriers faced by the industry. Kobos, Erickson, and Drennen (2016) showed that institutional policy instruments play an important role in enabling emerging RE technologies to cut costs and gain further market adoption.

Here, it is based on this literature review that we will set a course for our study. Different tools and mechanisms have been used in different countries to promote and encourage RE adoption. An EU directive sets a common pan-European framework with the use of renewable-resource energy in order to curb greenhouse gas emissions and promote cleaner, greener transport. The EU Member States are to establish national action plans which set the share of energy from renewable sources consumed in transport, as well as in the production of electricity and heat, for 2020. These action plans must take into account the effects of other energy efficiency measures on final gross energy consumption (the higher the reduction in energy consumption, the less energy from renewable sources will be required to meet the target). These plans will also establish procedures for reforming net metering, pricing schemes and grid access to promote energy from renewable sources.

In general terms, looking at the worldwide picture, some countries have used subsidies whereas others have used feed-in tariff (FIT) schemes, some have let the free market do the work, whereas some have forced their national utilities to purchase a specific percentage of RE (Kobos, Erickson, \& Drennen, 2016).

Given the obvious inescapable issues tied to fossil fuels, including the availability of fossil fuels in years to come, RE could well be the key to the energy future.

However, consumption patterns are also changing, and demand for the new product hinges on added value in terms of comfort, economics, social-environmental benefits. New products need to be technologically and economically viable to be successful. Furthermore, the product also needs a support package, i.e., information, awareness, maintenance, quality standards, and R\&D-driven improvement (Arnesano, Carlucci, \& Laforgia, 2012). The introduction of new technologies thus hinges on three factors (Abmann, Laumanns, \& Dieter, 2006):

- The policy framework needs to consider future developments;

- The new technology needs to be budgeted for;

- There has to be a supportive environment, such as capacities for information and awareness.

Thus, these criteria to maximize the promotion of new technologies and RE energy are integrated into the mission duties of French business clusters like CAPENERGIES. 


\section{Corsican as an Exemplary Case}

Corsica is an island economy marked by the complete absence of any of the big holdings and multinationals that fuel and forge the worldwide economy. Equally rare is the kind of medium-sized enterprises that has spearheaded local economies in other regions like Lombardy. Corsica's economic fabric is essentially made up of small and home businesses, farm smallholdings, artisans and small-scale retail. Given how public-sector capital investment is already hypertrophied, the private sector looks like the only viable option capable of triggering a dynamic regional development impetus. It would necessarily entail coordinatedly forging a dual strategy of training up human resources and engaging a technology research process aimed at increasing the needed island-wide competency levels to national and international competency standards frameworks.

\section{From the Plan for the PADDUC}

To insure the validity and reliability of the questionnaire, this research consulted the mature scales in foreign references in the process of operational definition and measurement of the variables like customer satisfaction and customer loyalty. The other latent variables as online shop image, online shopping expectations, and shopping experience also adopt operational definitions, but due to the lack of the scale suits to the theory framework of the research, on the basis of empirical research, we developed the measurement variables of the relative scale.

Under a central government-sponsored mission devolved to the Corsica-region local government (CTC) via French decentralization policy on Corsica under French government decree 2002-92 dated 22 January 2002 concerning Corsica, the CTC holds authority over development of the PADDUC. The plan sets objectives for island-wide economic, social, cultural, and tourist development, in tandem with environmental conservation measures. Paraphrasing article 12 of decree 2002-92, the plan defines the basic strategies underpinning physical infrastructure, multimodal transport, telecommunications, development of energy resources, and the protection and preservation of the island's territory. These strategies respect the objectives and principles laid down in articles L. 110 and L. 121-1 of the French code of urban planning. PADDUC sets principles for locating major transport and infrastructure, natural spaces, sites and landscapes to preserve, urban sprawl, and industrial, handcraft, commercial, agricultural, forest, tourist, cultural and sports activities. Highly strategic for the future of the island, PADDUC, which is currently still at the project level, stalled by particularly tense negotiations and ideological and political clashes, carries a sense of timelessness that some feel reinforces its legitimacy for the construction of a functional outline for the local economy.

\section{Plan for RE Development and Energy Control (ENR-MDE)}

Corsica is the only region that has created a permanent institution for consultation specifically designed to examine local energy issues: the Corsica Energy Council. The council draws geographic boundaries and seeks to characterize a model of sustainable development and viable energy management that would make Corsica an exemplary territory in the Mediterranean region. To this end, the Executive Council of Corsica drafted a Plan for Renewable Energy Development and Energy Management (ENR-MDE) that was pushed through the Corsican Assembly in November 2007. This Plan aims to bring the fraction of RE in the Corsican energy mixed from $21 \%$ today (already 10 points higher than the national average) to $34 \%$ in $2015-2020$. The Plan is built around three core strands:

- rationalize electricity consumption;

- promote the transition to RE for electricity generation (thermal, solar, and wood energy);

- develop RE technologies for electricity generation (photovoltaic, wind, and micro-hydraulic). 
Energy control and the switch to RE (thermal, solar, wood energy) should stem the growth curve of electricity demand from 3.8\% per year today to $3.1 \%$ per year in 2013 and $2.3 \%$ per year in 2020 . Forecasts on energy control (MDE) point to $2.9 \%$ electricity saved in 2013 and $11.9 \%$ in 2020 . Forecasts on the switch to RE (thermal solar and wood energy) point to $1.2 \%$ electricity saved in 2013 and $2.6 \%$ in 2020 . Wood energy essentially means replacing fuel oil or gas, and could further cut energy demand in these areas by $1.8 \%$ in 2013 and $3.6 \%$ in $2020^{2}$.

With the "ENR-MDE" Plan, the CTC has introduced a raft of tools and measures making RE central to development strategy and integral to the brand image of Corsica - targets include accelerating the adoption of RE-powered or energy-control devices by making them compulsory in all new builds, and integrating an eco-conditionality on subsidies to businesses and local authorities. Other strategies have also been tabled, such as projects to install compact fluorescent lamps (CFLs) across the island, to promote the development of wood-fired heating networks, and to create an energy audit enabling individuals to regulate any contractor that undertakes an ENR or MDE installation.

In this island region where energy security - sustainable development issues are cornerstones of political will and a citizen-led efforts to softly monetize outstanding environmental assets, the CAPENERGIES business cluster established under as a strategy to promote the adoption of greenhouse gas-free energy offers a real opportunity to concomitantly further local development and regional brand attractiveness.

\section{From Business Cluster to the Regional Brand Attractiveness: The Opportunity Offered by CAPENERGIES-Corsica}

In a globalizing world, the concept of regional branding takes on major significance, particularly in the field of development policy. Camagni (2002) stated that a competitive territory is one with a local advantage and a dynamic nature. Traditional elements such as available labour and capital now play a less significant role. Now, companies are looking for an effective territorial organization. It is through high-performance local industrial infrastructure that new technologies are managed and connections among different economic agents are quickly made. Any territory where productive infrastructure, quality of human capital, and quality of environment are all failing runs the risk of becoming marginalized. In this context, institutional and political forces have an acute responsibility to foster the creation of specific resources.

In sum, in the current globalization dynamic, a firm will permanently establish itself in a territory if and only if it offers technological potential and qualified and responsive human capital. Firms will not locate in a place where the local human capital lags behind. Public action is a vital driver of attraction factors, including stimulating the emergence of industrial districts where the trio virtuous innovation-technological research - applied vocational skills is optimized through human capital development strategy (Colletis \& Levet, 1997). This is precisely the vested goal of the CAPENERGIES business cluster, led by its "Corsica Center Energy" delegation created by the interdepartmental Committee on Local Territory Development and Competitiveness (CIACT) in October 2005.

\section{Research and Technology Transfer Enabling the Emergence of a Corsican Territorial Dynamic}

Corsica is a case-in-point illustration of an imbalanced island economy dominated by downstream trade and

\footnotetext{
2 Interview with the President of the Executive Council of Corsica, CTC; May 15, 2008. Source: Retrieved from http://www.capernergies.fr/index.php.
} 
non-market services near to final demand and structurally weak in terms of upstream production chain. Accordingly, upstream production is sorely needed. Among the means available to achieve this objective, a major strategic priority is to develop activities driving research and technology transfer in an organization based on partnership approaches designed to unleash synergies and promote collaborative work on innovative projects.

With this in mind, CAPENERGIES intends to re-energize Corsica as a territory of excellence and a hub of sustainable energy efficiency and RE development. Corsica's natural factor endowments and its place on the map make it ideally positioned to play a lead role in this area. The positioning of Corsica as a RE leadership centre meets several objectives:

- To develop and strengthen synergy between all stakeholders, be they public or private;

- To support a long-standing process aimed at promoting the use of RE;

- To accompany the strategy seeking to make renewables a source of wealth creation;

- To strengthen the capacity for training and R\&D.

This is about making RE an economic engine, a strategic base for R\&D and vocational skills, a real axis of expansion of the economic and social fabric of Corsica.

\section{Territorial Governance and Competitiveness Driving Corsica as a Regional Brand}

The past three years have seen a real dynamism operating in Corsica and the wider PACA region reached by CAPENERGIES, sparking a surge in the number of projects reviewed, approved, and funded ${ }^{3}$ (see Figure 1) up almost 500\% from 2009 to 2011, including an approval rate of $75 \%$. The total amount of projects approved amounted to $€ 560 \mathrm{M}$, including $€ 130 \mathrm{M}$ in funding. The distribution of financial backers is illustrated in Figure 2. Almost $60 \%$ of funding is from the French National Research Agency (ANR). The most promising sectors are biomass, projects linked to energy control, and solar-related projects (see Figure 3).

Creating the cluster enabled synergies between the actors involved, as $37 \%$ of approved projects count more than five partners, $54 \%$ count three to five partners, and less than $10 \%$ of projects count less than three partners.

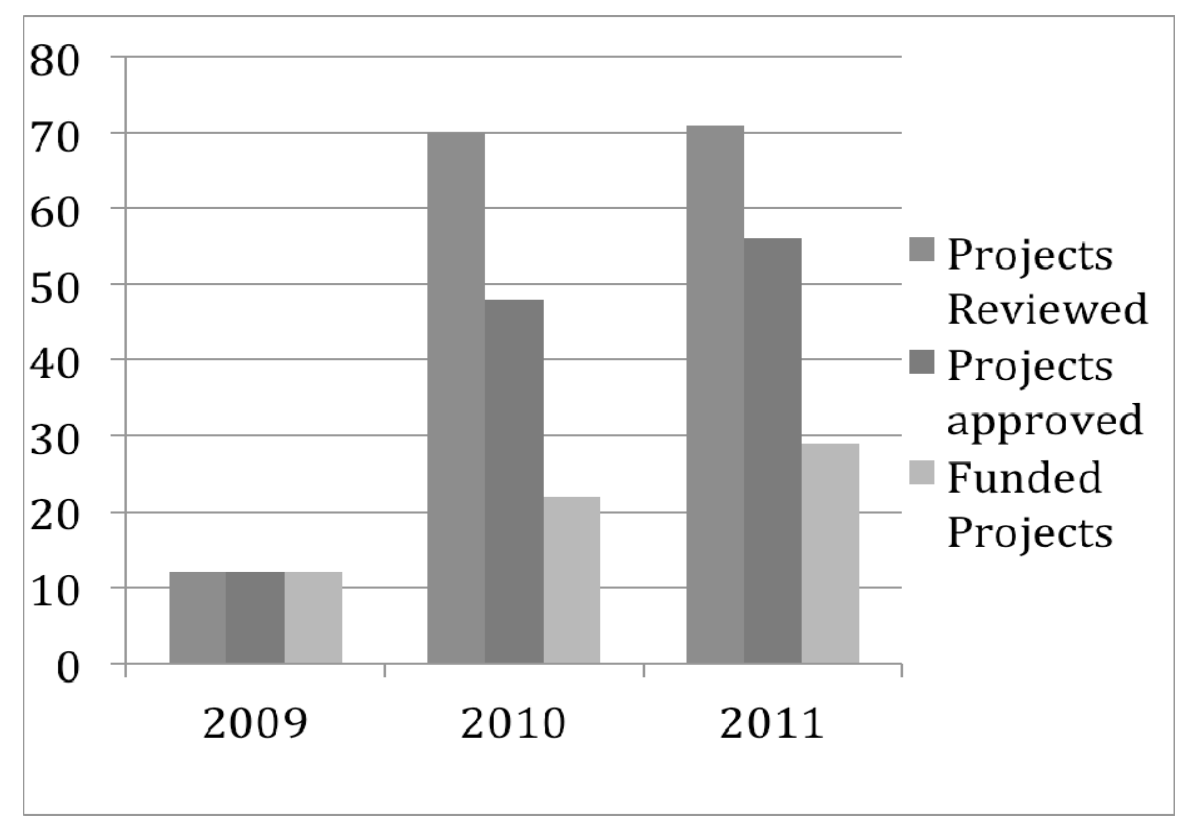

Figure 1. Evolution of the number of projects

${ }^{3}$ The data presented in the table and figure below are from the CAPENERGIES observatory. 


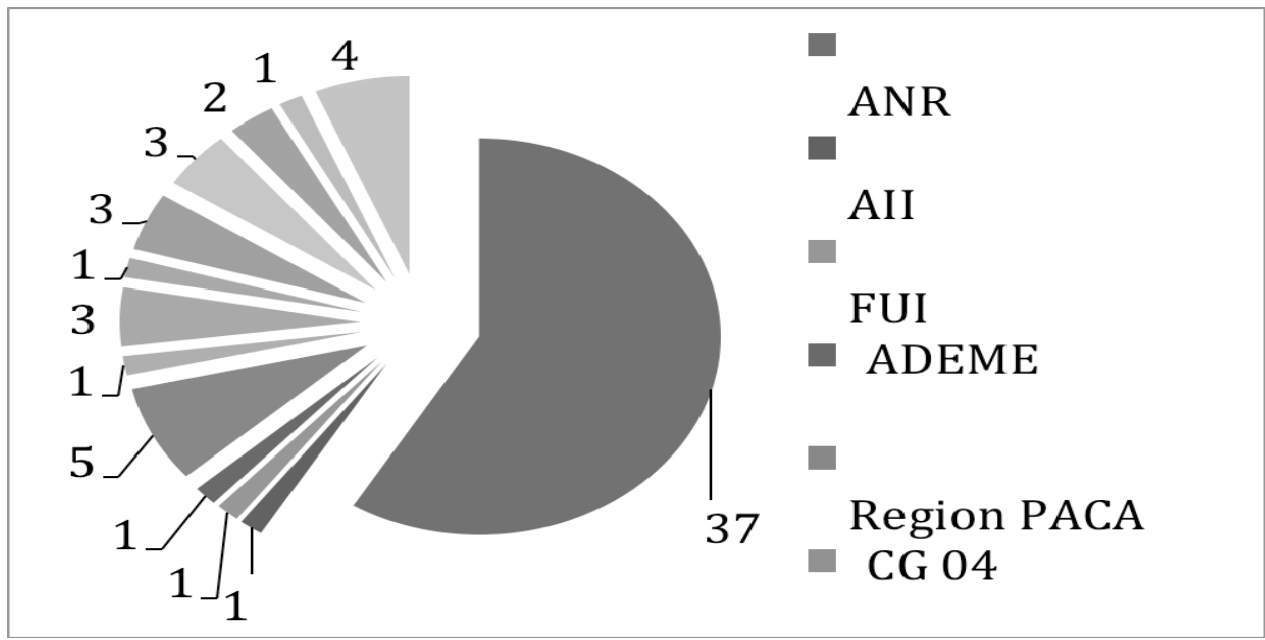

Figure 2. Financial backers.

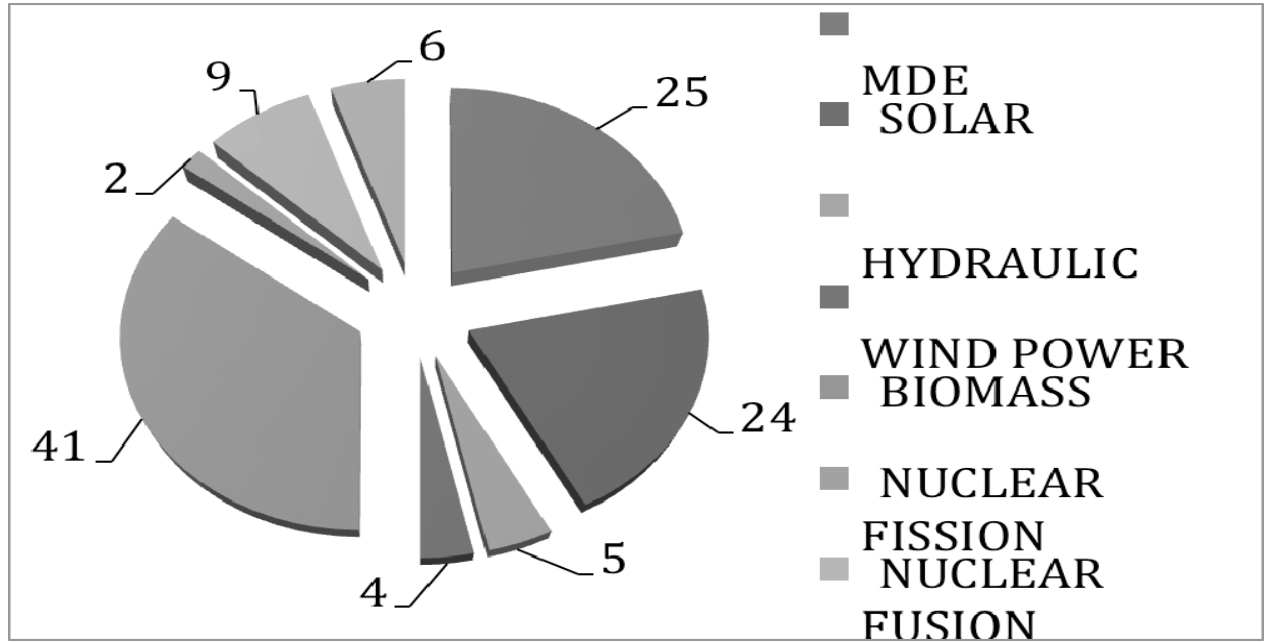

Figure 3. Areas concerned.

Conclusions

Created in 2005, the competitive clusters in the energy sector and their projects funded through various channels have sparked average year-on-year increases of $€ 100,000$ in R\&D expenditure and 1.3 full-time researcher or engineer jobs at the independent small businesses and medium-sized enterprises involved in the clusters over the 2006-2009 period.

The cluster initiatives designed to support growth through innovation have also increased turnover at these same independent small businesses and medium-sized enterprises, by an average $2 \%$ (i.e., $€ 1 \mathrm{M}$ ) per year. Direct public-sector funding to independent small businesses and medium-sized enterprise through their involvement in projects backed by cross-ministry funding ("FUI" scheme) amounts to $€ 45,000$, which equates to a leverage factor of over 2 . Consequently, the competitive clusters have fully played their role, as they have enabled businesses leading R\&D to net more of the benefits of public-funded innovation aid, such as by getting more of them to net tax breaks for research.

CAPENERGIES aims to be a benchmark, an engine for competitive growth of its many SMEs, based on the excellence of its research facilities, its training organizations, and engaged involvement of industrial 
groups. ${ }^{4}$ In this context, human capital and technological research are fundamental determinants in creating a plan for continual business pull and a structured territorial brand. Corsica, a small island economy seeking a sustainable development path, is effectively a macro-experiment on contextualized practice management and stakeholder organization.

In order to maximize the likelihood of success, Corsica must first accept the need for change, and then implement an appropriate organization and suitable methods. The Corsican strand of the CAPENERGIES business cluster federates training, research and industry to help structure the local territory by making it a more attractive regional brand. The real potential of regional brand development depends on measurable and evolving gradients. It also flows from a vision, from quantified objectives, from a patient analysis of strengths, weaknesses, opportunities, and threats, and only then can the means be mapped out through strategic initiatives. The alternative business cluster approach is based on acting within the system via a reorganization of its forces rather than on the system via an increase in means. In this way, it takes a lesson from beyond Corsica, substituting a project-based model for a "one-stop-shop" model. Thus, the bulk of investment comes as intangible resources, with an eye to sustainably transform relations among the actors participating in the development dynamic.

Although it is still too early to assess the impact of the method on the dynamics of innovation and job creation in Corsica, the Corsican strand of the CAPENERGIES business cluster has clearly federated hitherto-divided actors and platformed new bridges among the University of Corsica, research labs, and businesses. University governance on the island is now fully involved in the activities of the cluster, both for pure research and applied training. ${ }^{5}$ Local anchoring of R\&D projects (Vignola site, see Figure 4) is directly in sync with the territorial problems tied to sustainable development (“ENR-MDE” development plan).

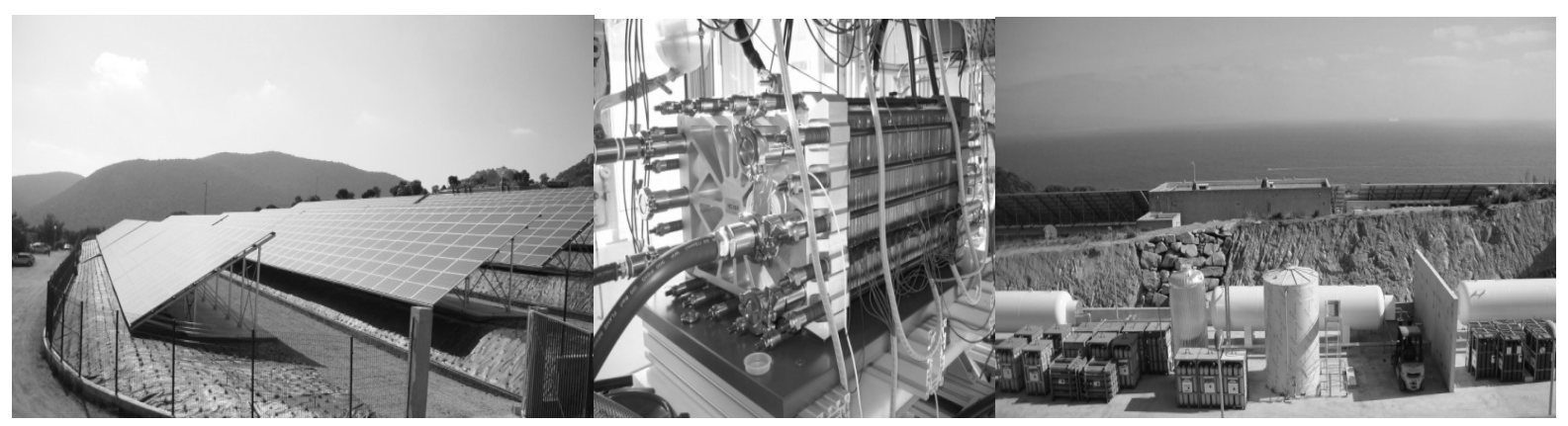

Figure 4. MYRTE.

In a region where youth, environment, cultural identity, and membership in the Euro-Mediterranean region are all invaluable assets, the potential for sustainable development created through knowledge and organization offers a tangible opportunity to achieve real regional attractiveness and less economic dependence.

Looking at the bigger picture for further development of competitive clusters, today's "project farms" are set to become tomorrows "next-generation product farms". The next phase in competitive cluster policy, which the government unveiled on 9 January 2013, is centred around consolidating the economic payoff of the policy. It features two core strands. The first strand aims to promote the transition from R\&D projects to innovative

\footnotetext{
${ }^{4}$ Its objective, in five years, is to become the worldwide benchmark for the integration and coupling of the energies of the future on isolated or island systems and fragile zones in larger interconnected networks.

5 The vast majority of the projects approved for the Corsica initiative have thus been made in partnership with the University of Corsica.
} 
marketable products and services in order to lend them greater impact in terms of jobs and profits. The clusters are therefore expected to back projects to build consortiums and alliances through to industrial rollout. The second strand, in tight complementarity with existing territory-wide initiatives, aims to galvanize the clusters as they work to support SMEs and foster a pro-SME environment, and thus to improve cluster performances in the process. Key, here, is access to private-sector backers, international reach of cluster members, support to SMEs (sponsorship and endorsement), and foresight on future skills needs. Domestic cluster policy is also evolving, and now reaches out to other regions of the country. These patterns of change can be expected to turn the clusters into "next-generation product farms" enabling the growth of renewables.

\section{References}

Abmann, D., Laumanns, U., \& Dieter, U. (2006). Renewable energy-A global review of technologies, policies and markets. London, UK: Earthscan.

Al-Amira, J., \& Abu-Hijlehb, B. (2013). Strategies and policies from promoting the use of renewable energy resources in the UAE. Renewable and Sustainable Energy Reviews, 26, 660-667.

Arnesano, M., Carlucci, A. P., \& Laforgia, D. (2012). Extension of portfolio theory application to energy planning problem-The Italian case. Energy, 39, 112-124.

Arnettea, A. N., \& Zobelb, C. W. (2011). The role of public policy in optimizing renewable energy development in the greater southern Appalachian mountains. Renewable and Sustainable Energy Reviews, 15, 3690-3702.

Boston Consulting Group (BCG) and CM International. (2008). Assessment of business clusters. Synthesis of Assessment Report, Paris.

Byrnes, L., Brown, C., Foster, J., \& Wagner, L. D. (2013). Australian renewable energy policy: Barriers and challenges. Renewable Energy, 60, 711-721.

Camagni, R. (2002). Territorial competitiveness, local environments and collective learning: A critical reflection. Journal of Urban and Regional Economics, No. 4.

Cherni, J., \& Kentish, J. (2007). Renewable energy policy and electricity market reforms in China. Energy Policy, 35, $3616-3629$.

Colletis, G., \& Levet, J. L. (1997). CGP, which policies are best for French industry?. Paris: la Documentation Française.

Hashim, H., \& Shin Ho, W. (2011). Renewable energy policies and initiatives for a sustainable energy future in Malaysia. Renewable and Sustainable Energy Reviews, 15, 4780-4787.

Jacquet, N., \& Darmon, D. (2005). Business clusters-The French model. Paris: La Documentation Française.

Kobos, P. H., Erickson, J. D., \& Drennen, T. E. (2016). Technological learning and renewable energy costs: Implications for US renewable energy policy. Energy Policy, 34, 1645-1658.

Lewis, J. I., \& Wier. R. H. (2007). A renewable energy technology industry: An international comparison of wind industry policy support mechanisms. Energy Policy, 35, 3067-3077.

Mair, A. (1994). Honda's global local corporation. New York: St. Martin's Press.

Mitchell, C., \& Connor, P. (2008). The EU's target for renewable energy: 20\% by 2020. Manchester: The Stationary Office.

Mondola, J. D., \& Koumpetsosb, N. (2013). Overview of challenges, prospects, environmental impacts and policies for renewable energy and sustainable development in Greece. Renewable and Sustainable Energy Reviews, 23, 431-442.

Storaï, C., \& Frimousse, S. (2010). Human capital training and technological research in the service of sustainable development. Corse: Corsica University Press.

Valle Costa, C., Rovere, E., \& Assmann, D. (2008). Technological innovation policies to promote renewable energies: Lessons from the European experience for the Brazilian case. Renewable and Sustainable Energy Reviews, 12, 65-90.

Wilma, P. (2009). Why have business clusters in France? Business dynamics. Paris: L'Harmattan. 